
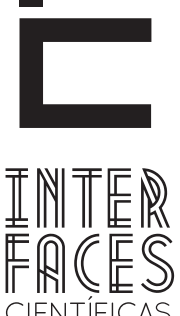

CIENTÍFICAS

HUMANASE SOCIAIS

\title{
O PATRIMÔNIO CULTURAL E CURRÍCULO: OS SENTIDOS DE JUVENTUDES EM QUESTÃO
}

Raquel ALS Venera ${ }^{1}$

\section{RESUMO}

Este artigo apresenta parte dos resultados da uma dissertação de mestrado em Patrimônio Cultural e Sociedade, especialmente no ponto em que se aproximaram os campos do Patrimônio Cultural e da Educação de forma interdisciplinar a partir das Teorias do Discurso. A empiria analisada foi o texto do Programa Nacional de Inclusão de jovens: educação, qualificação e ação comunitária, ProJovem, de 2006. Uma política que funciona como um disparador de "currículos" para os jovens brasileiros de baixa renda e excluídos do mercado de trabalho. Interessou na pesquisa saber quais os sentidos de juventudes apresentados nesse texto e o discurso, posto nessa textualidade, enquanto agenciamentos de sentidos politicamente situados. Ernesto Laclau foi o principal teórico que fundamentou a metodologia e possibilitou tomar o conceito de juventude como 'significante vazio', e perceber a forma como ele vai se
Ana Glostri Andrade 2

construindo no contexto dessa política, em cadeias de equivalências em que concorrem para a conceituação hegemônica do termo. Na aproximação dos dois campos foi possível capturar as formas de vida dos jovens construídas dentro e fora da escola, como valorização de um patrimônio cultural juvenil e tomar o currículo escolar enquanto lócus de construção de sentidos sociais hegemônicos. 0 jovem de baixa renda, posto como vulnerável e pouco engajado pelo texto do programa, é convocado a integrar-se na sociedade por meio dos sentidos de trabalho e cidadania chancelados pelos conteúdos formais da escola.

\section{PALAVRAS-CHAVE}

Patrimônio Cultural. Currículo. Juventudes. Teoria do Discurso 


\section{ABSTRACT}

This article presents some results of a dissertation in Cultural Heritage and Society, especially at the point where they approached the fields of Cultural Heritage and Education in an interdisciplinary way from the Discourse Theory. The empirical analyzed was the text of the National Program for Youth Inclusion: education, training and community action, ProJovem, 2006. A policy that acts as a trigger of "curriculum" for Brazilian youngsters from low-income and excluded from the labor market. Interested in research to know which youths directions presented in this text and speech, since this textuality as assemblages of politically situated senses. Ernesto Laclau was the main theorist who grounded the methodology and allowed to take the concept of youth as 'empty signifier', and realize

\section{RESUMEN}

Este artículo presenta parte de los resultados de una disertación de maestrazgo en Patrimonio Cultural y Sociedad, especialmente en el punto en que se aproximaron los campos del Patrimonio Cultural y de la Educación de forma interdisciplinaria a partir de las Teorías del Discurso. La empírica analizada fue el texto del Programa Nacional de Inclusión de Jóvenes: educación, calificación y acción comunitaria, ProJovem, de 2006. Una política que funciona como un disparador de "currículos" para los jóvenes brasileños de baja renta y fuera del mercado de trabajo. Interesó en la investigación saber cuál es los sentidos de juventudes presentados en ese texto y el discurso, puesto en ese contexto, mientras gestiones de sentidos políticamente situados. Ernesto Laclau es el principal teórico que fundamentó la metodología y posibilitó tomar el concepto de juventud como "significante vacío", y percibirla forma como él va construyéndose en el how it is being built in the context of this policy, in equivalence chains in contributing to the hegemonic definition of the term. On the approach of the two fields was possible to capture the ways of life of young people built inside and outside the school, as recovery of a youth cultural heritage and take the school curriculum as locus of construction of hegemonic social meanings. The young low-income, vulnerable and put as little engaged by the program text, is summoned to integrate into society through work senses and citizenship chancelados by school formal contents.

\section{KEYWORDS}

Cultural Heritage. Resume. Youths. Discourse Theory.

contexto de esa política, encadenas de equivalencias en que concurren para la conceptuación hegemónica del término. En la aproximación de los dos campos fue posible capturar las formas de vida de los jóvenes construidas dentro y fuera de la escuela, como valorización de un patrimonio cultural juvenil y tomar el currículo escolar en cuanto loco de construcción de sentidos sociales hegemónicos. El joven de baja renta, puesto como vulnerable y poco comprometido por el texto del programa, integrarse en la sociedad a través de los sentidos de trabajo y ciudadanías por contenidos formales de la escuela.

\section{PALABRAS CLAVE}

Patrimonio Cultural. Currículo. Juventudes. Teoría del Discurso 


\section{INTRODUÇÃO}

Lá onde nossa linguagem autoriza a presumir um corpo, e não existe corpo algum, lá desejaríamos dizer, existe um espírito.

(Wittgenstein, 1999, p. 41)

A epígrafe de Wittgenstein nos coloca frente à inquietação de pensar os sujeitos nos jogos de linguagem, sem nenhuma base ou segurança de uma dada essência que os garanta, previamente, um conceito, uma definição, uma identidade. Lá, onde os discursos fazem sentidos, os jogos de linguagem são jogados, as articulações políticas são alçadas, os seres humanos são nominados e lá autorizamos "a presumir um corpo", onde as subjetividades se processam desautomatizadas de essências.

Este artigo se debruça no desafio de compreender como se estabelece o processo de construção de sentidos que definem as juventudes no maior programa de inclusão de Jovens, ProJovem ${ }^{3}$, da Secretaria Nacional de Juventude. É parte de uma pesquisa que analisa o discurso de um dos primeiros textos do ProJovem, em 2006, a partir de ferramentas da Teoria do Discurso de Ernesto Laclau.

Para esse artigo em especial privilegiou-se os recortes da análise que desenham "cadeias de equivalências" de sentidos para juventudes, percebendo uma tentativa do jogo de linguagem de construir um sentido hegemônico para juventude. Dessa forma, não se trata aqui de analisar todo o documento, nem de itens específicos dele, mas privilegiou-se do todo, sentidos que emergiram como associação metonímica à juventude. Trata-se de parte do desafio de entender como no jogo de linguagem se faz aparecer sentidos políticos em um contexto privilegiado na educação da juventude no Brasil.

De acordo com o IBGE temos no Brasil 34 milhões de jovens entre 15 e 24 anos. Isso significa dizer que

3. ProJovem Original que regulamentou as atividades de 235 mil jovens entre 2005 e 2007. Disponível em: <www.projovem.gov.br> nunca tivemos tantos jovens/adolescentes entre nós, e, de acordo com os índices de natalidade que a mesma instituição apresenta, não teremos nos próximos anos a repetição deste fenômeno. Nesse contexto, a aproximação com as políticas públicas para essa parcela da população tem suscitado questionamentos acerca de como estamos nos tornando o que somos e têm colocado a prova os nossos horizontes de expectativas, e isso, implica na responsabilidade educativa sobre os mais jovens e na forma como essas subjetividades entram no jogo de linguagem e construção de sentidos.

$E$, essa questão, permeia de formas diferentes os campos do Currículo e do Patrimônio Cultural, aqui tomados como lócus tensional no interior do ProJovem. Entre a valorização de modos de vida, produções culturais, saberes, valores, memórias e as demandas contemporâneas do novo, da mudança, do descarte borram tensionamento tanto curriculares quanto patrimoniais.

O ProJovem foi pensado, a princípio, para os jovens das capitais e regiões metropolitanas do país, que em 2004, no escopo da Política Nacional de Juventude (PNJ) haviam sido mapeados em um universo de 4,5 milhões de brasileiros de 15 a 29 anos e que não completaram o Ensino Fundamental, além de estarem fora do mercado de trabalho, e sem direito a uma vida cidadã. 0 grande desafio de programas com essa natureza é garantir o direito de acesso aos saberes escolares que são, historicamente, construídos e legitimados a partir de referenciais nos saberes científicos, e, portanto, agregados de valores simbólicos que prometem, em tese, a emancipação humana.

Esses saberes disponíveis nas instituições escolares são tomados neste artigo como patrimônios culturais tradicionais, dotados de uma aposta política de promoção de identidades, representações sociais e memórias coletivas emancipadoras. Além disso, esses jovens, despossuídos desse patrimônio cultural, pos- 
suem modos de vida, produção de cultura e saberes não científicos que também são patrimônios e legados do seu grupo e que passam a ser considerados nos processos de subjetivações no interior do currículo de formação do ProJovem.

Neste sentido, um dos objetivos dessa política é, em tese, o encurtamento da distância entre as condições sociais de grande parte de jovens e as regras curriculares para a passagem por esses saberes escolares considerados fundamentos para a vida adulta, útil e produtiva sem que percam de vista suas produções culturais.

Ao aproximarmos as Teorias do Currículo ao campo do Patrimônio Cultural, consideramos os saberes e práticas curriculares como patrimônios culturais. Isto porque, diferentemente das Teorias do Currículo tradicionais, que pensam o currículo de forma fixa, estática, e apenas escolar, esse artigo assume o currículo e cultura como: prática de significação, prática produtiva, relação social, relação de poder e prática que produz identidades (SILVA, 1999).

\begin{abstract}
Da mesma forma que a cultura, também o currículo pode ser visto como uma prática de significação. Também o currículo pode ser visto como um texto, como uma trama de significados, pode ser analisado como um discurso e ser visto como uma prática discursiva. E como prática de significação, o currículo, tal como a cultura, é, sobretudo, uma prática produtiva. (SILVA, 1999, p. 19).
\end{abstract}

Tanto os campos do currículo, como do patrimônio cultural facilitam nesta análise o entendimento de que os jogos de linguagem estão na centralidade das disputas por hegemonias. Os sentidos de juventudes funcionam no interior desses campos como jogos de linguagem, como sistemas sempre abertos a polissemia, nos quais as práticas discursivas se fazem - discursos e práticas amalgamadas.

Interpretar os discursos da política de currículo, ProJovem, é descrever um elemento de cultura que, posto no arranjo das múltiplas culturas contemporâ- neas, intenta visibilizarem um processo de construção de identidades juvenis que não é neutro e se faz no jogo da linguagem. Pressupomos que a juventude é um conceito que, ao ser posto no jogo de construção de sentidos se dispara em uma multiplicidade.

Ao tentar definir o jovem alvo do programa e suas características e, ao estabelecer conteúdos para a sua emancipação, o texto atribui sentidos que vão moldando o conceito de juventude. Nesta análise o conceito será tratado no plural por entender que as tentativas de sua definição tem se mostrado irremediavelmente fracassadas. Nossa intenção ao utilizar as teorias do currículo e as reflexões do campo do patrimônio cultural é pensa-las enquanto parte do jogo discursivo de construção de identidades de juventudes desejadas.

Para essas análises esse artigo aposta na potencia dos conceitos da Teoria do Discurso pensada por Ernesto Laclau e concorda com o uso dela a favor das análises de políticas educacionais como os argumentos construídos por Alice Cassimiro Lopes (2011). Diferente da abordagem do ciclo de políticas, bastante comum nas análises desse gênero, a viabilidade oferecida por essa abordagem discursiva, nas palavras da autora, implica considerar, também:

[...] negociações de sentidos em busca da hegemonia de um determinado sentido que, provisória e contingencialmente, ocupa um centro capaz de aglutinar os sentidos postos em disputa, mas que nunca é pleno e nem implica a possibilidade de fechamento total da significação. (LOPES, 2011, p. 31).

Para tanto, esse artigo está organizado em duas partes. Na primeira parte intitulada "Currículo e Patrimônio" buscou-se argumentar a favor da opção de aproximação dos campos do Currículo e do Patrimônio Cultural como lócus dialógico no qual os sentidos de juventudes foram analisados, além dos conceitos e ferramentas que fundamentaram esse artigo. A segunda parte é constituída de dois blocos de análises intitulados "Cadeia de Equivalência 1 e Cadeia de Equivalência 2", em uma tentativa de evidenciar como 
são organizados movimentos metonímicos no texto, ou seja, uma sequência de sentidos que colam no significante vazio "juventude" e passa a funcionar como catacreses que justificam a própria política ProJovem.

\section{CURRÍCULO E PATRIMÔNIO}

Recuperamos nesta proposta, por analogia, a potencialidade do paradigma interdisciplinar. Embora não se trata de disciplinas fechadas e os campos do Currículo e do Patrimônio Cultural são, na sua interioridade, constitutivos de interdisciplinaridades, reconhece-se que fazer pesquisa é uma intervenção política na construção ou consolidação de um campo. Dessa forma, a aproximação de dois campos aparentemente diferentes e um possível diálogo que evidencie convergências epistemológicas opera no sentido de criar regimes de visibilidade de pensamentos no paradigma interdisciplinar. Ao contrário do que pode parecer um enfraquecimento de ambos os campos, mas o fortalecimento daquilo que, produzido na sua interioridade, transborda diálogos na sua exterioridade.

A intencionalidade de aproximação e distanciamento de dois campos consolidados como o Currículo e o Patrimônio Cultural implica em considerar dois movimentos constitutivos do fazer pesquisa. Por um lado a ampliação conceitual que ambos os campos viveram, especialmente nos anos de 1990, e, por outro lado, o recorte próprio da delimitação discursiva e conceitual.

Na medida em que se estende o conceito em um movimento na busca da compreensão da dinâmica social de sua produção e fixação dos seus sentidos, se cria um problema de definição. Se quase tudo pode se mostrar como um currículo ou um patrimônio, a instabilidade de definição conceitual faz com que seus sentidos políticos se fragilizem. Diante das lutas concorrenciais de um campo intelectual não se faz estranho à presença de um cuidado por uma medida de estabilidade conceitual sobre os objetos e teorias desenvolvidas pelos intelectuais envolvidos e uma marca de legitimidade e autoridade sobre quem pode dizer e sobre o que se diz dentro desses campos.

Esses dois movimentos aparentemente antagônicos não são entendidos aqui em oposição, ao contrário, são lados diferentes de uma mesma moeda e trata-se do ponto nodal desse argumento. É no momento em que os campos do Currículo e do Patrimônio Cultural se ampliam que faz possível um ponto de intersecção entre eles, mas é no cuidado da retração, que ambos se definem e tornam consolidados e podem, por isso, estabelecer diálogo a partir de um lugar epistemológico.

O historiador Dominique Poulot (2009, p. 14) ao historiar o campo do Patrimônio Cultual no ocidente sugere haver três imaginários sobre o patrimônio, como o "lugar da pessoa pública, em particular a figura do rei, lugar da história edificada, lugar da identidade cultural”. Além desses imaginários são também possíveis de ser mapeada uma operação que toca a legitimação, que por sua vez, convoca o aspecto técnico antropológico, histórico e jurídico e, por conta disso, justifica-se a necessidade pedagógica de sua transmissão, muito comum nos projetos de educação patrimonial, por exemplo. Ao mesmo tempo, outra operação relaciona-se à identidade e cultura, e nesse aspecto, o patrimônio cultural não perde sua natureza educativa, porém, ganha sentidos mais amplos relacionados ao exercício da cidadania e a expressão da democracia.

Interessou-nos, aqui evocar um sentido mais ampliado de patrimônio cultural, que não se limita a legislação nem as narrativas que sustentam os laudos técnicos de legitimidade ou originalidade, mas destacam-se os lugares de produção de identidade cultural, as apropriações e reconfigurações de saberes e formas de vida. Nesse aspecto, ao contrário de defender uma pureza de origem, uma essência fundadora em uma dada materialidade patrimonial, constata-se no fluxo cultural os jogos de tempo, ou seja, as demandas de um presente - no nosso caso específico a educação de jovens excluídos -, que acionam as expectativas de 
futuro pela qual se luta - identidades de futuros adultos produtivos, úteis, saudáveis e cidadãos - e os passados pelos quais se quer preservar - os saberes científicos acionados nos currículos escolares, os saberes industriais, nas formas de "civilidade" cotidiana.

O patrimônio cultural é currículo na medida em que é capaz de estruturar conjuntos de significações semelhantes, infere sentido de juventude, invoca identidades e estrutura-se na memória de juventude em um dado tempo (presente).

No campo do currículo a escolha foi trabalhar com o currículo como local privilegiado de significações, exercido, como destaca Sandra Corazza (2010. p. 107), em qualquer comunidade formal ou informal "locais de trabalho e lazer, campo, cais, ilhas, praças, pátios, associações, ginásios, ruas, assentamentos, parques, viadutos, até em escolas", e incluímos nos patrimônios culturais, que, por sua vez, também, pode ser experimentado em todos os espaços em que um ser humano pode ser subjetivado pelos fluxos de memórias, evocações de identidades e representações sobre si e sobre os grupos culturais a sua volta.

Ao aproximar o currículo e o patrimônio cultural observa-se que os dois campos de produção de conhecimentos experimentaram trajetórias teóricas críticas semelhantes em que as categorias de classes sociais são postas em evidencias. As transformações sociais e políticas do século XX emprestaram aos dois campos - 0 Currículo e do Patrimônio Cultural - um contexto de mudanças de perspectivas e o reconhecimento de "novos patrimônios" e "novos currículos" que estendem desde os já conhecidos objetos e arquiteturas salvaguardados por legislações e técnicas de preservação, até os mais diversos saberes e modos de vida de múltiplas comunidades, classes, tribos ou grupos sociais que vão se mostrando no espaço democrático na luta concorrencial pelo direito a memória, a identidade e as representações.

O caminho teórico desta análise privilegiou alguns conceitos trabalhados por Ernesto Laclau (2012), mais especificamente das teorias sobre "hegemonia", "cadeias de equivalências" e "significante vazio". Para este cientista político e teórico do discurso, os processos sociais de disputas identitárias, disputas por hegemonia, são expressos no domínio de significação do espaço cultural. Instituições, grupos sociais, classes sociais e pessoas no poder significam o mundo social.

Por hegemonia entende-se, então, uma evidencia de que a totalidade está sempre ausente e, diante dessa ausência original, se faz as tentativas dos diversos concorrenciais lutarem por uma positividade, sempre incompletas. É preciso haver os espaços vazios a ser preenchido pela política para que o processo hegemônico se movimente. Essa análise entende as juventudes como 'significante vazio' que uma vez no jogo das políticas curriculares, como por exemplo o ProJovem, experimenta a incontornável possiblidade de se preencher e dispara 'cadeias de equivalência' de sentidos concorrenciais. Por 'cadeia de equivalência' entende-se, então, as conexões de diferentes componentes, mas que de alguma forma possuem algo em comum que os agrega na direção da homogeneização de um sentido, mas ao mesmo tempo o difere, garantindo assim uma multiplicidade de desdobramentos no interior da cadeia.

Celi Regina Pinto (1999, p. 85) ao explicar a forma como a lógica pela qual a equivalência se processa na luta por hegemonia esclarece, a partir de Laclau e Mouffe, que: "se A, B e C são equivalentes, existe obrigatoriamente um termo que não é $A$, nem $B$ nem C e que me permite identificar a equivalência”. As diferenças são apagadas, mesmo que provisoriamente, a partir do significante vazio, que nunca cessa de solicitar significações. Nas palavras de Alice Cassimiro Lopes (2011, p. 35):

O significante vazio é, portanto, um elemento importante na constituição de todo sistema de significação, já que tem a função de articular, na cadeia de equivalência que torna possível a hegemonização de um determinado projeto, os elementos equivalentes, apagando, provisoriamente, as diferenças. [...] Em síntese, 
a cadeia de equivalência que possibilita a hegemonização de um determinado sentido precisa de um lugar vazio a ser preenchido pela política.

De volta à juventude entendida nessa análise como significante vazio, observa-se que, as diferentes políticas direcionadas a esses sujeitos, tentam defini-los cronologicamente ou com outros sentidos. No caso específico da política do ProJovem, ao defini-los se inicia uma cadeia de equivalências, ou seja: sujeitos entre idade $x$ e y, sujeitos em fase de formação, sujeitos em situações de risco entre outros, ordenando sentidos $A, B, C$. No entanto, os sentidos se esgotam nesse grande vazio e surgem programas mais específicos como "ProJovem Urbano" "ProJovem do campo", “ProJovem Adolescente”, “ProJovem Trabalhador”, ProJovem Indígena” entre outros. Aqui está um exemplo de que a definição de juventude é um lugar vazio a ser preenchido pela política e ao fazê-lo, põe em movimento cadeias concorrencial de sentidos hegemônicos para a juventude.

Esse processo de hegemonização, de construção das cadeias de equivalência é, ao mesmo tempo, uma inclusão e uma exclusão, associa e dissocia significantes na medida em que preenche, provisoriamente, o significante vazio. "A presença de significantes vazios - no sentido que temos definido - é a própria condição da hegemonia" (LACLAU, 2012, p. 77). Isto, porque para que haja hegemonia é preciso que haja, antes, espaço de disputa pela significação. “A operação hegemônica seria a apresentação da particularidade de um grupo como a encarnação do significante vazio que faz referência à ordem comunitária como uma ausência, uma realidade não preenchida" (LACLAU, 2012, p. 77).

Hegemonizar é cumprir a função de preenchimento do significante vazio. A relação entre hegemonia e significante vazio se põe na condição hegemônica de significação do significante vazio no discurso. Este processo de significação só se realiza, porque existem antes espaços políticos de disputa de poder, espaços que se circunscrevem em conceitos vazios. A juventude, tomada aqui como um significante vazio, é este espaço que revela disputas de poder por significação.

\section{CADEIA DE EQUIVALÊNCIA $1-A$ VULNERABILIDADE}

O texto do segundo capítulo do ProJovem "Juventude brasileira: vulnerabilidades e potencialidades" (BRASIL, 2006, p. 6) apresenta os sistemas de significações de juventude em seus critérios: etário, socioeconômico, culturais, de expectativa de vida, escolaridade na construção do perfil do jovem marginalizado, vulnerável, que fundamenta a justificativa do programa. 0 título do capítulo e o subtítulo dizem sobre o "perfil socioeconômico" e por consequência a “vulnerabilidades” (BRASIL, 2006, p. 6).

O sentido de vulnerabilidade pela condição socioeconômica referida pelos mecanismos de exclusão social. Os dados que significam esta condição vulnerável do jovem apresentam: “ $58,7 \%$ vivia em famílias que tinham uma renda per capita menor que 1 salário mínimo". O texto justifica a vulnerabilidade colando-o ao sentido de juventude em quatro itens aqui reproduzidos: o acesso restrito a educação e frágeis condições para a permanência nos sistemas escolares, a inadequação da qualificação para o mundo do trabalho, o envolvimento com drogas, a gravidez precoce, as mortes por causas externas (homicídio, trânsito e suicídio) e o baixo acesso às atividades de esporte, lazer e cultura (BRASIL, 2006, p. 6).

Supondo que a vulnerabilidade constitua um dos sentidos na cadeia de equivalência para os jovens pobres, quantificados em $58,7 \%$, o texto faz uma generalização na busca pela universalização da vulnerabilidade bastante limitada. Após elencar os itens que reproduzimos acima, o texto coloca:

Se esses problemas, com pesos bastante diferenciados, dizem respeito à grande maioria dos jovens bra- 
sileiros quando examinamos a situação particular dos jovens de 18 a 24 anos verifica-se que constituem o grupo mais vulnerável da sociedade brasileira. (BRASIL, 2006, p. 7).

A quantidade, os 58,7\% não representa "grande maioria", mas maioria. A palavra "grande" adjetiva o jovem, o universo das diferentes juventudes, enquanto vulnerável. Ainda no mesmo parágrafo, indica a não contestabilidade desse sentido ao propor "os dados a seguir confirmam esse quadro de vulnerabilidade". Existe claramente um desejo de hegemonização de sentidos. 0 texto apresenta como prova da vulnerabilidade juvenil, dados da Pesquisa Nacional por Amostra de Domicílios (PNAD) de 2003. A forma como a estrutura do texto apresenta os dados, destaca, dos 23,4 miIhões de jovens, 6,1 milhões que somam os analfabetos (753,4 mil) e os que não concluíram o Ensino Fundamental (5,4 milhões). A forma como os dados são apresentados maximiza este universo de $26 \%$.

0 texto seguinte evidencia a generalização da vulnerabilidade: "Precocemente afastados da escola, grande parte dos 23,4 milhões, também não estavam inseridos no mercado de trabalho formal". A palavra "também" impõe uma segunda generalização, como se, além de fora da escola, também estivessem "os jovens" (em geral), fora do mercado de trabalho formal.

No parágrafo seguinte do texto, o sentido de "vulnerabilidade" é evocado como parte da cadeia de equivalências de juventude em, pelo menos, dois momentos: "os dados anteriores seriam suficientes para identificar esse grupo etário como o segmento juvenil particularmente atingido pelo processo de exclusão social", e "mas há ainda outras dimensões que devem ser consideradas para melhor caracterizar-se a situação de vulnerabilidade em que se encontram", quando abre o discurso para novos recortes e generalizações.

Dos jovens atingidos pelo processo de exclusão social a que nos referimos acima: são eles: "jovens de 18 a 24 anos, residentes nas regiões metropolitanas, que estão fora da escola e que não possuem vínculos formais de trabalho" (BRASIL, 2006, p. 7).

Os dados da violência nas grandes cidades - que atingem efetivamente $37 \%$ dos jovens brasileiros são universalizantes. A tentativa de construir um discurso hegemônico, que justifique as políticas públicas para a juventude, é fundamentada em dados, pesquisas e instituições com autoridade de fala. Entre as pesquisas citadas, os nomes IBGE - Censo, Ministério da Saúde e UNESCO vêm legitimar um discurso e esse artifício compõe um jogo de linguagem. Um exemplo desse jogo de linguagem pode ser lido na frase "A violência das grandes cidades atinge particularmente os jovens" (BRASIL, 2006, p. 8).

O “particularmente” é vazio na medida em que não caracteriza a incidência da violência entre jovens em comparação a outras faixas etárias, mas para um leitor desatento, parece construir a imagem de que a violência nas grandes cidades atinge, quase unanimemente, os jovens. As sequencias de frases no mesmo parágrafo constrói essa representação. "Segundo dados do Ministério da Saúde [...] em 2002, morreram no Brasil 28 mil jovens de 20 a 24 anos, sendo que $72 \%$ das mortes foram ocasionadas por causas externas” (BRASIL, 2006, p. 8).

Como já apontamos, o dado não mostra o universo das mortes não naturais, externas, como agressão (homicídio), acidentes de transporte, afogamento, entre outros. "Os jovens do sexo masculino foram o alvo prioritário dessas perdas: 18,5 mil mortes, o que corresponde a $80 \%$ do total" (BRASIL, 2006 , p. 8). Vale lembrar que estes $80 \%$ estão em relação aos $72 \%$ das mortes de causa externa da faixa etária supracitada, e que não apresenta relação com outros tipos de mortes, não externas, ou com os outros grupos etários.

Não estamos tentando minimizar o problema da violência entre os jovens no Brasil, que é uma questão política bastante problemática quan- 
do situamo-nos entre os países mais violentos do mundo. Nossa intenção é destacar que os sentidos de juventudes estão impressos em um jogo de linguagem, generalizamos a tal ponto a violência na caracterização da vulnerabilidade dos jovens brasileiros que o sentido da palavra "vulnerabilidade" se cola ao sentido de juventude. A vulnerabilidade passa ser parte da cadeia de equivalência desse significante vazio no movimento político da construção hegemônica.

\section{CADEIA DE EQUIVALÊNCIA 2-O ENGAJAMENTO E OUTROS SENTIDOS}

No item 2.2 do texto do programa ProJovem, "Protagonismo e participação social: potencialidades" (BRASIL, 2006, p. 9), o texto apresenta o exercício da cidadania como engajamento social. Cidadania é um significante bastante caro para a nossa análise e não pretendemos dar conta dessa discussão aqui. A relação entre potencialidades e cidadania é clara no texto quando, a problematização parte do "pouco engajamento social dos jovens" - argumentado com dados estatísticos do UNICEF, do Projeto Juventude do Instituto Cidadania e do Projeto Juventude -, e da vontade deles de se engajarem. 0 texto defende a necessidade de um programa social que evoque o jovem à "participação cidadã”.

O início do trecho do texto em questão aponta generalizações sobre o senso comum de juventude. No primeiro parágrafo: "No cenário atual, a sociedade costuma ver a juventude como sinônimo de problema e como motivo de preocupação quanto ao futuro do País" (BRASIL, 2006, p. 9), a primeira sentença afirma a juventude enquanto: problema e preocupação, indo ao encontro do significante vulnerável já construído no texto anterior.

O uso de vozes legítimas continua no jogo da linguagem quando argumenta dados da UNICEF em que
"65\% dos adolescentes (12 a 17 anos) nunca participaram de atividades associativas e ou comunitárias" ou ainda que o Projeto Juventude do Instituto Cidadania, entre os jovens (14 a 24 anos), apenas uma minoria atua formalmente em movimentos estudantis, sindicatos, entre outros e no Projeto Juventude, parte significativa dos jovens "disse que gostaria de ter oportunidade de participar de ações desenvolvidas em contextos sociais, comunitários e cidadãos" (BRASIL, 2006, p. 9).

Ou seja, o texto defende que o jovem precisa engajar-se em atividades sociais, tem energia para tanto, mas não o faz. Ou pelo menos não dentro das estruturas sociais sob o controle do Estado. 0 item do projeto sobre protagonismo e participação social, que significa juventude por suas potencialidades, fecha com 0 seguinte parágrafo:

\begin{abstract}
A juventude é a fase da vida mais marcada por ambivalências, pela convivência contraditória dos elementos de emancipação e de subordinação, sempre em choque e negociação. Mas essa também é a fase de maior energia, generosidade e potencial para o engajamento. Portanto, um programa dirigido aos jovens deve tomar como seus tanto os desafios que estão sendo colocados para essa geração, quanto sua forma inovadora de encontrar respostas aos problemas sociais, chamando-os permanentemente para o diálogo e para a participação cidadã. (BRASIL, 2006, p. 10 ).
\end{abstract}

Esse trecho abre a cadeia de equivalências em um contínuo: juventude = uma fase da vida, portanto tem um sentido etário; juventude = fase tensa entre emancipação e subordinação; juventude = fase de energia; juventude = fase de generosidade; juventude $=$ fase de potencial para engajamentos. Ao aproximar o sentido de engajamento à juventude esse texto joga com outros sentidos e amplia a cadeia de equivalências. 0 potencial e a energia vêm acompanhados da ambivalência entre a vulnerabilidade e a necessidade ainda de subordinação. 0 sentido de vulnerabilidade continua desencadeando outros sentidos metafóricos aos jovens. 


\section{REFLEXÕES FINAIS}

Os jovens, ao passarem pelo currículo do ProJovem, são identificados com o sentido de vulnerável, agente potencial, cidadão e trabalhador na construção de suas identidades juvenis. 0 texto, ao apresentar o jovem, enquanto marginalizado, significa a diferença, o que se põe de modo antagônico ao processo de identificação e inserção na sociedade.

A partir da cadeia de equivalência que produz 0 jogo de linguagem desse currículo, a juventude se forma, também, os sentidos argumentativos para a normalização da identidade do jovem trabalhador-cidadão e o fixa em relações de poder que voltam a colocá-lo à margem, mas uma margem dentro da estrutura de poder e controle do Estado. Dessa forma a aproximação dos campos do currículo e do patrimônio nos permitiu perceber que aquilo que se pode nominar como "patrimônios culturais tradicionais" dentro de um currículo escolar, acaba por oferecer aos jovens uma possibilidade de "passaporte" para o mundo do trabalho. Um patrimônio de uma cultura que estabelece representações, pertencimentos e constrói identidades a favor do mundo do trabalho.

O currículo do ProJovem aproximado ao campo do patrimônio cultural desenha nos jogos de linguagem em análise, as estrutura, os saberes culturais que devem ser perpetuados para que os jovens estabeleçam relações de identificação em sociedade. É neste sentido que afirmamos que o currículo é patrimônio cultural na medida em que é capaz de estruturar modos de pensar, agir e sentir, memorar e se constituir no mundo. 0 currículo subjetiva "lá onde nossa linguagem autoriza a presumir um corpo" como a citação da epigrafe desse artigo.

As análises aqui apresentadas evidenciou o campo do currículo enquanto elemento de identificação e significação que, apesar de fluido nas sociedades contemporâneas, encontra nos patrimônios culturais as possibilidades de manutenção e construção das relações sociais no Brasil contemporâneo. A política curricular expressa no ProJovem acaba por valorizar alguns sentidos e saberes como patrimônios culturais que concorre para a hegemonização de uma conceituação de juventude vulnerável, pouco engajada e que se integra na sociedade por meio das equivalências de trabalho e cidadania.

\section{REFERÊNCIAS}

BRASIL, República Federativa do. Programa Nacional de Inclusão de Jovens: Educação, Qualificação e Ação Comunitária - PROJOVEM. 2006. Disponível em <www.projovem.org.br>. Acesso em: 4 jun. 2012.

CORAZZA, Sandra Mara. Diferença pura de um pós-currículo. In: LOPES, Alice Cassimiro, MACEDO, Elizabete. Currículo: debates contemporâneos. 3.ed. São Paulo: Cortez, 2010.

LACLAU, Ernesto. Emancipação e Diferença. Tradução Alice Cassimiro Lopes e Elizabete Macedo. Rio de Janeiro: EDUERJ, 2012.

LACLAU, Ernesto. A política e os limites da modernidade. In: HOLLANDA, H. B.(Org.). Pós-Modernismo e política. Rio de Janeiro: Rocco, 1991, p.127-150.

OLIVEIRA, Ana de; LOPES. Alice Cassimiro. A abordagem do ciclo de políticas: uma leitura pela teoria do discurso. Revista Caderno de Educação, n.38. Programa de Pós-graduação em Educação da Universidade Federal de Pelotas, 2011, p.19-41.

PINTO, Celi Regina Jardim. Democracia como significante vazio: a propósito das teses de Ernesto Laclau e Chantal Mouffe. Revista Sociologias, v.1, n.2, 1999, p.68-99.

POULOT, Dominique. Uma história do patrimônio no Ocidente. São Paulo: Estação Liberdade, 2009. 
SILVA, Tomaz Tadeu. (Org.). Identidade e diferença: a perspectiva dos estudos culturais. Petrópolis: Vozes, 2000.

SILVA, Tomaz Tadeu. 0 currículo como fetiche: a poética e a política do texto curricular. Belo Horizonte: Autentica, 1999.

WITTGENSTEIN, Ludwig. Investigações Filosóficas. São Paulo: Nova Cultura, 1999. 